\title{
O ADVENTO DA MODERNA CRÍTICA LITERÁRIA NA FRANÇA DO SÉCULO XIX: DE MME. DE STAËL A GUSTAVE LANSON*
}

\author{
Nabil Araújo de Souza**
}

Resumo: A moderna crítica literária nasce na França, em principios do século XIX, sob o signo do Romantismo, da ascensão do Autor e da História no horizonte da literatura, há pouco ainda inclusa nas belles-lettres. Este texto recupera o desenvolvimento interno do paradigma histórico/biográfico da critica acadêmica francesa, de Mme. de Staël (1766-1817) a Gustave Lanson (1857-1934).

\section{INTRODUÇÃO}

O mesmo caráter de divisor de águas convencionalmente atribuído ao século XVII na história da Física haveria de ser conferido, a tomar por base um certo senso comum a respeito, ao século XIX na história dos Estudos Literários. Assim, se com a chamada Revolução Científica - impulsionada, como se sabe, por obra de um Kepler, de um Galileu, de um Newton, na esteira de uma revolução inicial, dita copernicana —, diz-se assistir ao nascimento da ciência moderna, em oposição à "ciência antiga", de base aristotélica, com a revolução romântica dos oitocentos - tida por contraparte estética da revolução política de 1789 - dir-se-ia assistir ao nascimento da moderna crítica literária, em oposição à "crítica antiga", de feição retoricista, que vigorara até fins do século XVIII. Tamanho o peso conferido por um autor como Albert Thibaudet à alegada ruptura que o mesmo não se furtaria a sublinhar, no prefácio de sua célebre Physiologie de la critique: "A crítica, tal qual nós a conhecemos e praticamos, é um produto do século XIX. Antes do século XIX, havia críticos. Bayle, Fréron e Voltaire, Chapelain e D'Aubignac,

\footnotetext{
'Recebido para publicação em agosto de 2006.

"Mestrando do Pós-Lit — Programa de Pós-Graduação em Letras da Faculdade de Letras/UFMG.
} 
Denys de Halicarnasso e Quintiliano foram críticos. Mas a crítica não havia", (THIBAUDET, 1948:8).

Dentre os fatores que teriam possibilitado o surgimento da moderna crítica literária no século XIX, Thibaudet (1948:8-16) destaca três: (i) um primeiro, a que chamaríamos institucional, e que consiste no fato de que "o nascimento da corporação crítica tem lugar em função do nascimento de duas outras corporações, inexistentes antes do século XIX, a dos professores e a dos jornalistas", as quais teriam dado origem a dois tipos de crítica distintos, opostos e rivais; (ii) um segundo, a que chamaríamos propriamente epistemológico, e que diz respeito à consolidação de uma consciência e de uma disciplina históricas a possibilitarem a instrumentalização do que Thibaudet considera a tendência natural da crítica ao "inventário" - e, aqui, reforçarse-ia a distinção entre uma crítica dos jornalistas, voltada "ao discernimento do presente", e uma crítica dos professores, voltada, então, "ao inventário do passado"; (iii) e um terceiro, a que chamaríamos político, e que diz respeito à consolidação de um liberalismo e um pluralismo estéticos, ou a "um direito igualmente reconhecido em relação a sistemas de gosto e planos de criação diversos", cujo primeiro passo teria sido o reconhecimento da dicotomia entre clássico e romântico.

Invertendo a ordem de apresentação dos fatores: politico > epistemológico > institucional, o que aí se constataria, na verdade, é o seguinte processo: dada a relativização dos gostos, dos valores e dos juízos num ambiente pós-revolucionário, a história - conjugada à sociologia e à psicologia - consagra-se como forma privilegiada e, mesmo, hegemônica, de apreensão e explicação do fenômeno literário, sendo institucionalizada como tal pelo ensino acadêmico, que busca sistematizar e tornar positivo o conhecimento que produz. Consolida-se, dessa forma, um conhecimento literário dito especializado.

A fim de analisar esse processo mais detidamente, partamos, aqui, da imagem que nos oferece Bourget (1965:291-292) do ambiente cultural e intelectual a partir do qual haveria de germinar a moderna crítica literária:

1 Esta e as demais traduções do francês neste texto são de nossa autoria. 
"Rebentou a revolução de 1789, seguiu-se-lhe o Império. As grandes guerras daqueles vinte e cinco anos tiveram o inesperado efeito de misturar singularmente as naçōes umas com as outras. Para nos limitarmos à França, essas convulsões sociais, precipitando para fora de seu país um Chateaubriand, uma Madame de Staël, um Paul-Louis Courier, um Benjamin Constant e tantos outros, fizeram-lhes saber que existia uma Europa. Não se limitaram a ler no texto Shakespeare, Dante e Goethe, como teria feito em 1780 um jovem francês curioso, que soubesse línguas. Leram-nos no próprio local, no seu país de origem, e sentiram o íntimo laço que unia essas obras-primas da literatura aos costumes, ao céu, à alma enfim da Inglaterra, da Itália, da Alemanha. Destrinçaram, confusamente uns, mais nitidamente outros, duas verdades de que os seus predecessores não suspeitaram; a primeira, que em toda a criação de arte há alguma coisa mais do que um esforço de estética, que essa criação constitui uma necessária e quase inconsciente manifestação de todos esses elementos de que é feito o gênio nacional: qualidades da raça, momento da história, influência do clima; a segunda, que existem muitos tipos de beleza diferentes, senão contraditórios, e que o gosto não tem de modo algum esse caráter fixo de que as Poéticas e Retóricas da idade clássica faziam um dogma".

O edifício da retórica clássica, sob o qual assentava o estudo das "belas letras" desde a Antigüidade, sucumbia, pois, sob a dupla revolução — política e estética — de fins do século XVIII, início do século XIX. ${ }^{2}$ Já não era mais possível, com efeito, para a crítica, limitar-se a verificar a adequação ou não de uma dada obra a esta ou aquela regra de produção discursiva, segundo os ditames retoricistas: ante o reconhecimento da diversidade de padrões estéticos, tornava-se mister, doravante, explicar a obra em função dos diversos fatores - históricos, culturais, sociológicos, psicológicos - que determinariam sua constituição. "A crítica no século XIX perseguirá dois fins: explicar a obra e julgá-la. Mas seu avanço extraordinário se realizará em

\footnotetext{
${ }^{2}$ Abordamos a gênese, o desenvolvimento e o ocaso do paradigma classicista/retoricista da crítica ocidental no segundo capítulo de nossa dissertação de mestrado (SOUZA, 2006).
} 
um só sentido, no da explicação. Antes de julgar é necessário compreender", explica, com efeito, Bonet (1969:38); e completa: "Esta norma é norte comum para uma cadeia de críticos máximos que atravessa o século XIX. O primeiro elo, Mme. de Staël".

\section{MADAME DE STAËL (1766-1817)}

Em seu influente De la littérature considerée dans ses rapports avec les institutions sociales (1800), obra cujo título, por si só, constituía um novo programa de estudo literário, Mme. de Staël expôs as bases do que haveria de se impor, ao longo do século, como a postura ideal da crítica em relação às obras de que se ocupa. Na abertura do "Discurso preliminar" ao livro, num trecho a se tornar antológico, a autora afirmava ter se proposto "examinar qual é a influência da religião, dos costumes e das leis sobre a literatura, e qual é a influência da literatura sobre a religião, os costumes e as leis". (DE STAEL, 1935:9). "Nessas palavras", diz-nos Bonet (1969:44-45), "já se insinua a crítica explicativa e determinista que irá dominar o século XIX e reduzir cada vez mais o papel da valorização dogmática".

"Examinarei, antes de mais nada, a literatura de uma maneira geral em suas relações com a virtude, a glória, a liberdade e a felicidade", afirmava, ainda, de Staël (1935:10); conclamava, assim, a seus leitores que se the unissem "para acompanhar o progresso e para observar o caráter dominante dos escritores de cada país e de cada século". É, portanto, dupla a relativização por ela entrevista: no tempo e no espaço. Impunha-se já, aí, dessa forma, a historicização do fenômeno literário, que haveria de institucionalizar-se, mais tarde, com a ascensão e a consolidação da história literária positivista.

Admiradora dos românticos alemães, com alguns dos quais estreitara relações quando de duas viagens suas à Alemanha, em 1803 e 1807, Madame de Staël dos mesmos se diferenciava no modo de conceber a apreensão e a investigação da literatura. A retomar um lugar comum, opunha-se-lhes como o esprit de clarté francês opõe-se à obscuridade metafísica alemã. Dela, seu amigo Schiller teria dito, em tom de reprovação: "Sua formosa inteligência chega quase à altura do gênio. Mas empenha-se em aclarar tudo: não vos concede nada obscuro e inacessível. Tudo o que não possa iluminar com a sua tocha é para ela como se não existisse". (apud BONET, 1969:49-50). 
Ora, essa obsessão por tudo aclarar e explicar converter-se-ia mesmo, como já dissemos, em traço determinante da nova teoria crítica. "O papel de Mme: de Staël, em literatura, foi o de compreender e de fazer compreender", diria, com efeito, Lanson (1912:881), em larga medida um herdeiro da autora.

Apesar de tomar, ainda, a literatura "em sua acepção a mais estendida", de Staël (1935:9) pressupunha claramente uma distinção entre o que chamava de "escritos filosóficos", por um lado, e de "obras de imaginação", por outro. Roger (2002:42-43) afirma a esse respeito que "o reconhecimento da especificidade das obras de ficção põe em relevo a 'obra', objeto da crítica, ao mesmo tempo que postula a existência do 'autor', noção tanto literária quanto social". E se à autora interessava a literatura menos como expressão do gênio individual do que do gênio coletivo ou nacional, encontram-se, contudo, em sua obra, trechos a prefigurar a voga do determinismo biográfico que tomaria conta, dentro em breve, da crítica literária oitocentista. Exemplos disso são as seguintes considerações sobre escritores alemães e suas obras, colhidas quase que aleatoriamente em seu De L'Allemagne, de 1810:

(1) "Schiller era o melhor amigo, o melhor pai, o melhor esposo; nenhuma qualidade faltava a esse caráter doce e pacífico que o talento inflamava; o amor à liberdade, o respeito pelas mulheres, o entusiasmo pelas belas-artes, a adoração à Divindade animavam seu gênio; e, na análise de seus trabalhos, será fácil mostrar à que virtude tais obras de arte se reportam" (DE STAËL, 1935:64);

(2) [Sobre Werther]: "vê-se aí tudo o que o gênio de Goethe podia produzir quando estava apaixonado. Diz-se que ele atribui atualmente pouco valor a essa obra de sua juventude, a efervescência de imaginação que o inspirou quase ao entusiasmo pelo suicídio deve the parecer agora repreensível. Quando se é muito jovem, a degradação do ser não tendo em nada começado, o túmulo não parece senão uma imagem poética, um sono cercado de figuras ajoelhadas que choram por nós" (DE STAËL, 1935:79); 
(3) "Novalis, homem de nascimento ilustre, iniciara-se desde a juventude nos estudos de todo gênero que a nova escola tinha desenvolvido na Alemanha; mas sua alma piedosa deu um grande caráter de simplicidade a suas poesias". (DE STAEL, 1935: 83).

Encontramo-nos aí a anos-luz da tradicional verificação-de-adequaçãoa-regras ditada pela preceptística classicista: é justamente a exceção à regra, ou a excepcionalidade do escritor enraizada em suas idiossincrasias biográficas, que ora desempenha a função de baliza crítica. E se o recurso à vida e ao caráter do autor afigurava-se, com de Staël, ainda secundário, ele haveria de tornar-se, em contrapartida, com um Sainte-Beuve, admirador fervoroso daquela autora, nada menos que o procedimento crítico por excelência, cerne do "método biográfico" em crítica literária.

\section{SAINTE-BEUVE (1804-1869)}

Em alguma medida já se pode falar em método biográfico no que se refere ao trabalho de um Villemain (1790-1870), figura central da crítica francesa na primeira metade do século XIX, professor na Sorbonne e seguidor de de Staël; mas é apenas com os "portraits" de seu aluno Sainte-Beuve que haveria de consolidar-se uma crítica biográfica propriamente dita.

Parece ter sido em dois artigos de 1862, sobre Chateaubriand, coligidos em Nouveaux Lundis (1863-1870), que Sainte-Beuve mais diretamente expôs seu método crítico. "A literatura, a produção literária, não é para mim distinta ou, ao menos, dissociável do resto do homem", dizia ele então. (SAINTEBEUVE, 1964a:282). "Posso apreciar uma obra", continuava, "mas me é difícil julgá-la independentemente do conhecimento do homem mesmo; e diria de bom grado: tal árvore, tal fruto. $\mathrm{O}$ estudo literário leva-me, assim, de todo naturalmente ao estudo moral". Mas qual o procedimento, afinal, do crítico, em relação a seu novo objeto?

Enquanto não se tiver feito sobre o autor um certo número de perguntas, afirmava Sainte-Beuve (1964b:283-284), e enquanto não se as tiver respondido, não se pode estar certo de tê-lo apreendido inteiramente, "ainda que tais questões pareçam as mais estranhas à natureza de seus escritos". 
Questões do tipo: "- Que pensava o autor em matéria de religião? - Como era afetado pelo espetáculo da natureza? - Como se comportava em relação às mulheres? - em relação ao dinheiro? - Era rico, era pobre? - Qual o seu regime, sua maneira cotidiana de viver?, etc.". E finalmente: "- Qual era seu vício ou fraqueza? Todo homem tem um". (SAINTE-BEUVE, 1964b:284). "Nenhuma das respostas a essas questões é indiferente para julgar o autor de um livro e o próprio livro, se esse livro não for um tratado de geometria pura, se for, sobretudo, uma obra literária, ou seja, onde entra de tudo", concluía Sainte-Beuve (1964b:284).

Bonet (1969:63-70) nos oferece, a propósito, alguns exemplos de juízos biográficos à la Sainte-Beuve, tais como: (1) ao passo que o "sentimento da natureza" transbordaria em Rousseau e, por conseqüência, em sua obra, estaria ausente, por outro lado, num Boileau ou numa Madame de Staël e, portanto, de seus escritos; (2) a saúde debilitada de Pascal explicaria "o sério e grave do seu espírito, sua religiosidade, seu transcendentalismo dramático", ao passo que o "equilíbrio constante" das páginas de um Anatole France adviria de sua saúde igualmente equilibrada; (3) se na base da grandiosidade de Milton estaria sua cegueira, "pois o cego vive de recordações: em sua memória se volatizam as minúcias e com restos de imagens a fantasia constrói fábricas ideais", o "detalhismo descritivo" de Zola, por sua vez, seria indício de sua miopia.

Central, numa tal perspectiva analítica, é o problema da gênese da obra literária. O texto, aqui, é sempre algo insuficiente, no sentido de que não se lhe explica sem referência à sua origem, à sua causa primeira, a saber: seu autor. "Ao passo que a antiga crítica considerara um livro como uma coisa feita, que se devia examinar em si e por si", explica Bourget (1965:295-296), "SainteBeuve disse consigo que para compreender um livro era preciso considerá-lo como uma coisa a ser feita e examiná-la nas suas condições de nascença e execução". Ou ainda:

"Por trás da página escrita, quis ver a mão que a tinha escrito, o corpo a que pertencia essa mão, a idade e os hábitos desse corpo, o homem numa palavra, o indivíduo que respirava, que se movia, que vivia e de que o poema, o drama, o romance constituem gestos que se fixaram. 
Para penetrar deste modo um indivíduo é preciso representá-lo por dentro e por fora, isto é, reconstituir por um lado a sua psicologia e a sua fisiologia, por outro o seu meio social: a sua família, a sua classe, as idéias da sua época - e aí temos o ensaio crítico tornado numa pintura de costumes, e a mais rica, a mais significativa". (BOURGET, 1965:296).

Fisiologia, psicologia, sociologia do autor: entrevê-se, portanto, já com Sainte-Beuve, um certo desejo de ciência que haveria de alastrar-se e ganhar dimensões cada vez maiores em meio à crítica literária oitocentista. O próprio Sainte-Beuve, aliás, tomava a crítica biográfica por ele fundada como o provável alicerce de uma futura "ciência moral". "Dia virá [...] no qual a ciência será constituída, no qual as grandes famílias de espíritos e suas principais divisões serão determinadas e conhecidas", prenunciou o autor (SAINTE-BEUVE, 1964a:283). "Nós fazemos, por nossa conta, simples monografias, acumulamos observações de detalhes", ponderava, "mas eu entrevejo ligações, relações, e um espírito mais vasto, mais luminoso, e ainda fino no detalhe poderá descobrir, um dia, as grandes divisões naturais que respondem às famílias de espíritos". (SAINTE-BEUVE, 1964a:283).

"A esta tentação científica", lembra-nos Aguiar e Silva (1968:448), "opõe-se, porém, em Sainte-Beuve, a consciência muito aguda da impossibilidade de reduzir o espírito e os seus valores a fatos naturais, 0 sentimento fortíssimo do caráter irredutivelmente singular de qualquer grande escritor". Com efeito, para Sainte-Beuve (1964a:283), a futura ciência moral de que falava "seria sempre tão delicada e tão móvel que não existiria a não ser por meio daqueles que têm uma vocação natural e um talento de observar"; seria sempre, em outras palavras, "uma arte que demandaria um artista hábil, como a medicina exige o tato médico daquele que a exerce, como a filosofia deveria exigir o tato filosófico entre aqueles que se pretendem filósofos, como a poesia não se quer executada a não ser por um poeta".

Guiado por esse tipo de pudor, dedicado que estava mais a pintar seus retratos de autores do que a consolidar uma ciência dos espíritos propriamente dita, Sainte-Beuve não pouparia críticas às tentativas de então de tornar científica ou "positiva" a crítica literária. Seria preciso, pois, esperar pela 
obra de Hippolyte Taine - o grande alvo das referidas críticas - para ver alcançar sua forma talvez a mais incisiva o desejo de ciência da moderna crítica literária. E, contudo, não se pode tomá-la em desconsideração à senda aberta por seus predecessores, principalmente o próprio Sainte-Beuve.

\section{HIPPOLYTE TAINE (1828-1893)}

"Com Hippolyte Taine, a crítica determinista, iniciada por Mme. de Staël e reforçada por Villemain e Sainte-Beuve, alcança seu pleno desenvolvimento", afirma Bonet (1969:77). "Sainte-Beuve é o ascendente principal. Seu sistema crítico, sinuoso, dobrável, elástico, em Taine é disciplina científica. O que no primeiro se insinua ou fica difuso, no segundo se sistematiza e toma contornos precisos", arremata o autor. Seria equivocado, contudo, tomar a obra crítica de Taine como simplesmente uma sistematização da de Sainte-Beuve.

O ponto de partida é, sem dúvida, beuviano: "Todos sabem que as várias obras de um artista são parentes umas das outras, como filthas do mesmo pai, ou seja, que elas têm entre si notáveis semelhanças. Sabem que cada artista tem o seu estilo, um estilo que se encontra em todas as suas obras". (TAINE, 1964a:142). O desdobramento, contudo, desse parti pris determinista vai além: "O próprio artista, apreciado com a obra total que haja produzido, não existe isolado. Há também um conjunto em que ele é compreendido, conjunto maior do que ele e que é a escola ou a família de artistas do país e da época a que pertence". E mais: "A própria família de artistas está compreendida num conjunto mais vasto, que é o mundo que a cerca e cujo gosto está em harmonia com o seu. É que o estado dos costumes e do espírito é o mesmo para o público e para os artistas". Isso posto, estabelecer-se-ia como regra que "para se compreender uma obra de arte, um artista, um grupo de artistas, é necessário considerar-se rigorosamente o estado geral do espírito e dos costumes do tempo a que pertenceram". (TAINE, 1964a:143).

A passagem de Sainte-Beuve a Taine definir-se-ia bem como a passagem da pintura à explicação, como deixa entrever Aguiar e Silva (1968:449): "Sainte-Beuve pintava um autor, desde a sua adolescência e a sua época de formação até à sua maturidade e à sua velhice, acompanhando-o 
na curva do tempo em todas as suas experiências e mutações; Taine pretende explicar os fatos psicológicos colecionados e descritos por esse tipo de crítica". O percurso que vai do pintar ao explicar implicaria, contudo, para Taine, mais do que a simples sucessão natural entre etapas de um supostamente mesmo processo: o que separaria, na verdade, uma perspectiva da outra seria o mesmo que separa o mero descritivismo acumulativo do método científico ou positivo propriamente dito.

Respondiendo à crítica formulada por Sainte-Beuve e seus partidários de que o homem seria demasiado complexo para que se pudesse reduzi-lo ao método positivo que então pretendia impor-1he, Taine haveria de argumentar, como lembra Prado Coelho (1982:251), que tal "complexidade" verificar-se-ia apenas "para quem quer pintar, e não para quem escolhe por missão explicar, na medida em que, por definição, explicar é sempre reduzir o complexo a elementos únicos e decisivos". Daí a separação por ele entrevista entre uma crítica "que pinta" - que seria, sobretudo, uma arte - e uma crítica "que explica" - propriamente analítica ou filosófica. Aos adeptos da primeira, e em nome da segunda, Taine (1964b:290) retrucaria:

"deixai o objeto que forneceu matéria à pintura fornecer matéria à filosofia; permiti a análise vir depois da arte. Se é belo fazer ver um personagem, é talvez interessante fazer que se o compreenda. Os dois estudos diferem, uma vez que a imaginação difere da inteligência, e a razão tem o direito de decompor o que os olhos contemplaram e o que o coração sentiu. Eu posso me perguntar de onde vềm essas qualidades, esses defeitos, essas paixões, essas idéias; quais são os efeitos, quais são as causas; de que faculdades primitivas elas provêm; se, seguindo essas faculdades mais além, não se remontará a uma fonte comum; que massa e que sorte de sentimentos cada uma delas injetou na paixão total. As emoções e os pensamentos do homem estão ligados como as partes e os movimentos do corpo; e, uma vez que esse encadeamento merece ser notado no mundo corporal e visível, ele merece ser observado no mundo invisível e incorporal. Desde então, todos os vossos preceitos 
sucumbem; as regras que governam a pintura não se impõem à análise; o que seria um erro para a primeira torna-se um dever para a segunda. Vós desenvolveis, ela reduz. Vós perseguis os detalhes delicados, ela busca as grandes causas. Vós pegais no ar esses traços fugitivos que fazem surgir na imaginação toda uma figura; ela se atém às forças geradoras que produzem na vida toda uma série de acontecimentos".

Se a obra, de fato, parece remontar ao homem, o homem, por sua vez, lembra-nos Taine, remonta a certas "faculdades primitivas", as quais deveriam ser conhecidas e cuja influência sobre o homem e a obra deveria ser divisada e sistematicamente estudada. Sabe-se bem que para o autor _ e para o grosso da crítica determinista depois dele — tais faculdades resumir-se-iam a três: a raça, o meio e o momento. Assim:

(1) "Isso a que se chama a raça são as disposições inatas e hereditárias que o homem porta consigo ao nascer, e que ordinariamente são conjugadas às diferenças manifestadas no temperamento e na estrutura do corpo. Elas variam de acordo com os povos". (TAINE, 1953: $31)$;

(2) "Constatada a estrutura interior de uma raça, devese considerar o meio em que ela vive. Cedo o clima produziu seu efeito. [...] Cedo as circunstâncias políticas trabalharam [...]. Cedo, enfịm, as condições sociais imprimiram sua marca" (TAINE, 1953:32);

(3) "Quando o caráter nacional e as circunstâncias ambientais operam, não operam sobre uma tábua rasa, mas sobre uma tábua onde impressões estão já marcadas. Se se toma a tábua num momento ou em outro, a impressão é diferente; e isso basta para que o efeito total seja diferente": (TAINE, 1953:36). 
Isso posto, a literatura inglesa, por exemplo, haveria de ser tomada - lembra-nos Lanson (1912: 1045) a respeito - como "o produto da raça inglesa, sob dado clima, em dadas circunstâncias históricas, sob dadas crenças religiosas": Shakespeare, Milton, Tennyson seriam "resultantes", as quais representariam "forças aplicadas em diversos pontos"; já as Fábulas de La Fontaine explicar-se-iam "pelo caráter da Champagne, pátria do autor, pela vida que ele levou e pelos hábitos intelectuais e morais da sociedade do século XVII", ao passo que a tragédia francesa seria tomada como o que, na raça francesa, "devia dar a tradição antiga na corte de Luís XIV".

"Meu procedimento", proclamaria Taine (1964c:293), à guisa de síntese, "é completamente compreendido na observação de que as coisas morais, como as coisas físicas, possuem dependências e condições". Assim, aquelas seriam tão redutíveis ao método positivo quanto estas. E nesse ponto, mais do que em qualquer outro, Taine pareceu converter-se em exemplo privilegiado de sua própria teoria determinista, ao revelar-se inequivocamente um homem "de seu tempo".

Em meados do século XIX, sobretudo em França, a doutrina positivista bem como o dogma cientificista por ela implicada já haviam se tornado ideologia corrente. "Imbuído dessa atmosfera", lembra-nos Bonet (1969:79), "Taine, o normalista, fez-se homem de ciência, psicólogo, historiador". Aguiar e Silva (1968:449) observa, a propósito, que Taine consubstancia "as tendências mais representativas do pensamento europeu durante o período positivista". Indiciavam o positivismo de Taine, segundo Prado Coelho (1982:263), sobretudo "a sua valorização da idéia de ciência, o modo como ele situa a ciência no quadro do mundo moderno, dando-lhe um lugar central e decisivo no progresso da humanidade", além de "um sentimento muito vivo da realidade dos fatos, a necessidade do recurso à prova, ligação constante à experiência, verificação incessante de todas as afirmações, e, acima de tudo, um implacável espírito de crítica em relação a tudo: ao que se conhece e à forma de conhecer".

Taine teve muitos discípulos e seguidores, e sua influência haveria de tornar-se imensa ao longo da segunda metade do século XIX. Converteu-se seu nome, nesse contexto, em sinônimo de rigor è objetividade nos Estudos Literários. "Taine, como Sainte-Beuve, teve a consagração popular nos manuais", ressalta Bonet (1969:98). Deve-se a ele a consolidação da praxe 
em se encabeçar os períodos literários com um quadro sinóptico da estrutura social da época: "êxitos políticos", "instituições", "idéias e sentimentos dominantes", elementos tomados como "o conjunto das circunstâncias que se traduz na sensibilidade coletiva característica desse período histórico, e em função da qual os artistas entregam o melhor do seu espírito". (BONET, 1969:98).

Com a teoria crítica consolidada por obra de Taine, e de discípulos seus como Emile Hennequin (1858-1888) e Ferdinand Brunetière (1849-1907), a "ciência" havia de fato entrado, e ao que tudo indica irreversivelmente, no horizonte de expectativas dos Estudos Literários. E, nesse âmbito, já não haveria mais, doravante, como se furtar à discussão sobre o problema da cientificidade, ainda que fosse para professar, como o fizeram os críticos ditos "impressionistas" do fin-de-siècle francês, o mais profundo ceticismo em relação à possibilidade de uma crítica verdadeiramente científica ou objetiva, em qualquer nível que seja.

\section{A CRÍTICA IMPRESSIONISTA}

Sainte-Beuve já havia denunciado, como vimos, o que tomava por uma incapacidade arraigada do método crítico tainiano em abordar adequadamente a individualidade criativa em toda a sua alegada complexidade; observase, contudo, no percurso que leva de Sainte-Beuve a Taine, mais pontos de continuidade e prolongamento do que de dissensão ou ruptura. Críticos como Anatole France (1844-1924) e Jules Lemaître (1853-1914), por outro lado, haveriam de posicionar-se na mais inequívoca contramão do positivismo literário, contestando abertamente as pretensões cientificistas do mainstream da crítica francesa oitocentista, angariando, com isso, a hostilidade de autores como Brunetière, conhecido sobretudo por sua teoria evolucionista - declaradamente darwinista - dos gêneros literários.

"Tal como a entendo, a crítica é, como a filosofia e a história, uma espécie de romance para uso dos espíritos prudentes e curiosos; e todo romance, em última instância, é uma autobiografia. O bom crítico é aquele que narra as aventuras de sua alma em meio às obras-primas", afirmaria France (1964b: 305), em trecho a tornar-se antológico. "Com essas mansas palavras e esse tom, ao que parece, inofensivo", observa a respeito Bonet (1969:110), France 
"desautoriza todo um século de esforços, a empresa iniciada por Mme. de Staël e seguida, em França, por Villemain, Sainte-Beuve, Taine, Brunetière e uma nuvem de discípulos".

A ofensiva de France contra o edifício da crítica determinista ia bem além, como se vê, do argumento beuviano da irredutibilidade do "espírito" - alegado abjeto da crítica - ao método positivista à la Taine; voltavase, com efeito, ao próprio sujeito da crítica, à sua arraigada incapacidade de objetivar-se, por assim dizer, quando da atividade crítica. "Não há crítica objetiva como nã́o há arte objetiva", diz-nos France (1964b:305), "e todos os que se jactam de pôr outra coisa além de si mesmos em sua obra são vítimas da mais falaciosa ilusão. A verdade é que não se sai jamais de si mesmo. É uma de nossas maiores misérias".

Em consonância com o posicionamento do amigo, Lemaître (1964:312) já se havia indagado: "Como poderia a crítica literária constituirse em doutrina? As obras desfilam diante do espelho de nosso espírito; mas, como o desfile é longo, o espelho se modifica no intervalo, e quando por acaso a mesma obra retorna, ela não lhe projeta mais a mesma imagem". Assim: "dogmática ou não, a crítica, quaisquer que sejam suas pretensões, não vai jamais senão definir a impressão que provoca em nós, num dado momento, a obra de arte na qual o próprio escritor notou a impressão por ele recebida do mundo, em certo momento". (LEMAÎTRE, 1964:313).

Os impressionistas, sublinha Aguiar e Silva (1968: 455), "procuram transformar a crítica num diálogo de sua subjetividade com as obras-primas de todos os tempos, recolhem e apuram das suas leituras as impressões que mais fundamente marcam a sua sensibilidade, abandonam-se à sua fantasia e até aos seus caprichos de finos conhecedores da arte". Em suma, nada parece mais frontalmente opor-se ao determinismo cientificista dos críticos positivistas do que a visada impressionista. "Poucoș objetos no mundo são absolutamente submissos à ciência a ponto de se deixar ou reproduzir ou predizer por ela", proclamaria, com efeito, France (1964a:310). E ainda: "Sem dúvida, um poema não o será jamais, nem um poeta. [...] A beleza, a virtude, o gênio guardarão para sempre seu segredo".

Altissonante o suficiente para render certas rusgas com o status quo da crítica determinista da época, o impressionismo crítico não haveria de representar, contudo, ameaça efetiva ao domínio do positivismo literário no ambiente acadểmico. Observar-se-iam, isso sim, certas vozes dissonantes no 
interior da própria orientação positivista, as quais, longe de contribuírem para sua derrocada, teriam engendrado a sua perpetuação em vestes novas. Dentre elas, nenhuma mais decisiva que a de Gustave Lanson.

\section{GUSTAVE LANSON (1857-1934)}

À doutrina de Taine, Lanson (1912:1045) imputava "o defeito de tudo explicar": "ela não faz aparecer os elementos ainda inexplicáveis da obra literária. Ela desconsidera a natureza individual: não a do caráter, que é esclarecida pelas.influências compostas da raça, do momento e do meio, mas a do gênio, da precisão da vocação e da intensidade da criação". Assim: "Compreendo bem porque houve uma, tragédia francesa, mas por que o indivíduo Coneille, por que o indivíduo Racine compuseram tragédias?" (LANSON, 1912:1046). "Sem fazer intervir a liberdade", conclui Lanson, "há um efeito de que as três causas de Taine não se dão conta. [...] o escritor é determinado, a grandeza do escritor não é. Há aí um resíduo inexplicável, o qual se deve, na boa crítica, cuidadosamente resgatar". (LANSON, 1912:1046).

História e crítica literárias teriam, assim, por objetivo, o que Lanson (1912:VII;1964:320) chamava de "descrição de individualidades". Ele ressalta, a respeito, não se tratar de um retorno a Sainte-Beuve e seus portraits de autores. Sem negar o mérito próprio daquele a quem tomava por "um dos três ou quatro mestres da crítica de nosso século", Lanson (1964;320-321) reprovava-lhe o fato de ter reduzido a crítica quase que completamente à biografia, professando, inclusive, nesse ímpeto, a mais completa indistinção entre textos literários e não-literários. Se Sainte-Beuve, dessa forma, "fez bem o que se propôs a fazer", não se deveria, por outro lado, "generalizar seu método nem sobretudo lhe presumir um método completo e suficiente de conhecimento literário". (LANSON, 1964:321). Lanson reiterava, portanto, não querer dizer, com a expressão "descrição de individualidades",

"que se deve voltar ao método de Sainte-Beuve e constituir uma galeria de retratos; mas que, todos os meios de determinar a obra estando esgotados, uma vez restituído à raça, ao meio, ao momento o que lies pertence, uma vez considerada a continuidade da evolução do gênero, 
resta freqüientemente qualquer coisa que nenhuma dessas explicações alcança, que nenhuma dessas causas determina: e é precisamente nesse resíduo indeterminado, inexplicado, que está a originalidade superior da obra; esse resíduo é o aporte pessoal de Corneille e de Hugo, e que constitui sua individualidade literária". (LANSON, 1912:VII).

Tratar-se-ia, assim, "de alcançar não uma espécie, mas Corneille, mas Hugo", esclarece Lanson (1912:VII-VIII), "e se lhes alcança não por meio de experiências e procedimentos que todo mundo pode repetir e que fornecem a todos resultados invariáveis, mas pela aplicação de faculdades que, variáveis de homem para homem, fornecem resultados necessariamente relativos $\mathrm{e}$ incertos". Em suma: "Nem o objeto nem os meios do conhecimento literário são, a rigor, científicos".

Isso posto, enganar-se-ia quem julgasse aí reconhecer nada além de um elogio aberto e irrestrito ao impressionismo crítico; se Lanson admite, com efeito, o impressionismo, o faz tão-somente como um estrategista consciente de que para se superar um obstáculo mais vale identificá-lo e reconhecê-lo a contento do que simplesmente ignorá-lo. "O ideal de Lanson consiste em reconhecer os direitos da subjetividade e das impressões pessoais a fim de melhor as submeter ao 'controle' do método e da inteligência", sublinha, com efeito, Aguiar e Silva (1968:465).

Isso se mostra evidente no programa de estudo da literatura traçado por Lanson, o qual parte "do princípio de que todo julgamento literário completo é composto de dois elementos: informação histórica, elemento impessoal; apreciação da obra, elemento pessoal" (LANSON \& TUFFRAU, 1953: 758). No primeiro caso, tratar-se-ia de "resultados que não variam mais"; no segundo, de um elemento que, por sua própria natureza subjetiva, "escapa ao método". (LANSON \& TUFFRAU, 1953:758-759). Escapar ao método significa, aí, não ser passível de ensino ou transmissão metódica; o que não quer dizer que o que escapa ao método não possa ser controlado de alguma forma.

Não é gratuita, com efeito, a ordem das etapas apresentadas: a informação histórica, dita impessoal, precede e guia, ou controla, a atividade 
de apreciação e julgamento. Assim, ainda que tenha reafirmado, no que tange à sua monumental Histoire de la littérature française (1894), sua objeção em "resumir os julgamentos dos mestres que admiro, de Taine e de Sainte-Beuve, como de Gaston Paris e de Brunetière", por ter considerado mais útil, "numa matéria em que não há verdade dogmática nem racional", fazer valer suas próprias opiniões e impressões, Lanson (1912:X) ressalta ter se valido, para tanto, "de todos os trabalhos que poderiam fornecer noções positivas sobre os escritores e sobre os escritos: fatos biográficos ou bibliográficos, fontes, empréstimos, imitações, cronologia, etc.", pois esses seriam, conclui o autor, "elementos de informações que fazem compreender mais e melhor".

$O$ resultado dessa empreitada conhecem-no bem os estudantes de literatura francesa: uma narrativa pela qual vem-se a saber que os livros de Rabelais "exprimem o ideal de um homem nascido no povo, fugido do claustro, embriagado de liberdade e de ciência" (LANSON, 1912:250), e que o charme da linguagem de Montaigne "é o charme do espírito que a escreveu" (LANSON, 1912:325); que Racine explica-se sobretudo por "sua educação jansenista e seu sentimento do grego" (LANSON, 1912:544) e Voltaire pela subordinação progressiva do poeta dos "anos de aprendizagem" ao filósofo sarcástico da velhice (LANSON, 1912:689); que o "mecanismo mental" de Diderot compõe-se de "espontaneidade medíocre, reações prodigiosas" (LANSON, 1912:744) e que a origem do "dom de tristezas infinitas" de Lamartine encontra-se na obra de Chateaubriand (LANSON, 1912:948); que a prodigiosa imaginação financeira de Balzac, "perigosa na realidade, tornou-se uma grande qualidade literária para representar pelo romance uma sociedade onde os negócios e o dinheiro tinham tanto espaço" (LANSON, 1912:1001) e que Flaubert, apesar de naturalista, cultivava, em decorrência de sua educação e de suas admirações literárias — "Hugo era seu Deus" - "preconceitos e manias de romântico descabelado". (LANSON, 1912:1074). Aí, em suma, o mundo e a vida explicam o homem, e este explica a obra.

"O historiador literário, ao contrário do crítico impressionista, nunca concede aos seus sentimentos e reações pessoais um valor absoluto, esforçando-se constantemente por discipliná-los e por reduzi-los através da análise da obra, de estudos sobre a intenção do autor, as fontes, etc.", ressalta a propósito Aguiar e Silva (1968:465). Em suma: "Saber e sentir são duas realidades distintas e, na metodologia lansoniana, o sentir só se legitima quando 
conduz ao saber.".'(AGUIAR E SILVA, 1968: 466). Daí a difundida idéia de que Lanson "fixou, no limiar do século XX, as regras da História literária que iriam consideravelmente reduzir a parcela de arbitrariedade e de imprecisão na interpretação das obras". (LANSON \& TUFFRAU, 1953:758).

Prado Coelho (1982:278) destaca o reconhecimento, por parte de Lanson, de dois níveis de resistência da obra: (i) "o primeiro é o resto de subjetividade que se mostra irredutível à objetividade da ciência e nos condena a passar pelo impressionismo e a ficar parcialmente nele"; (ii) "o segundo nível é o do resto da obra que é irredutível à própria apreensão subjetiva [...]. Este resto da obra é já um resto do resto". Estes, então, dois riscos corridos pelo historiador literário: "face à resistência da subjetividade, ele corre o perigo de julgar que sabe quando apenas sente; face à resistência da obra, ele corre o risco de acabar por imaginar a obra na medida em que ela se recusa a ser plenamente observada". (PRADO COELHO, 1982:278). Logo, enfatiza Prado Coelho, o método da história literária consistiria justamente em eliminar esses riscos, "retificando o conhecimento e depurando os elementos subjetivos".

Explicita-se, assim, o positivismo de Lanson: "em primeiro lugar, considerando que em literatura encontramos fatos especiais, procura-se reduzir ao máximo essa especificidade; em segundo lugar, a colagem à realidade dos fatos deve ser total". (PRADO COELHO, 1982:280). Positivismo esse "que pretende, à sua maneira, ser lei", conclui Prado Coelho (1982:281), "ao legișar para todo o domínio dos estudos literários com tanta autoridade e exclusivismo que a subjetividade e o prazer da literatura se reduzem a um mínimo informulável que a ciência aceita para melhor poder definitivamente eliminar". Não estranha, assim, que se tenha dito que "Lanson pretende conservar o método de Taine, completando-o". (IBSCH \& FOKKEMA, 1983:32).

\section{CONCLUSÃO}

$\mathrm{Na}$ verdade, poder-se-ia tomar Lanson como o elemento de sintese da tradição determinista da crítica oitocentista francesa, essa tradição que nasce, como vimos, com Mme. de. Staël, desenvolve-se com Villemain e SainteBeuve, amadurece com Taine e Brunetière, e encontra no autor da Histoire de la littérature française um avaliador, um crítico, mas sobretudo, e ao mesmo 
tempo, um continuador - menos um epígono, é verdade, do que, em larga medida, um revisor. À vulgarização dessa síntese lansoniana deve-se a própria imagem de história literária que nos legou o século XIX - lapidarmente expressa, aliás, por um autor como Erich Auerbach, ao afirmar, já em pleno século XX:

\begin{abstract}
"desejamos que o historiador da literatura explique como determinado fenômeno literário pôde nascer, seja por influências antecedentes, seja pela situação social, histórica e política de onde se originou, seja pelo gênio peculiar de seu autor; e, neste último caso, exigimos que nos faça sentir as raízes biográficas e psicológicas desse gênio peculiar". (AUERBACH, 1972:31).
\end{abstract}

Isso posto, não estranha que, com a ascensão, nos anos 1950-1960, da chamada nouvelle critique francesa, essencialmente anti-histórica e antibiográfica, quando se tratava de denominar o próprio regime de estudo literário ao qual então se opunham os vanguardiștas não raro se o tenha feito por meio do vocábulo lansonismo. Não é coincidência, além do mais, que a guerra então travada contra o "lansonismo" tenha sido declarada sob a bandeira de um certo renascimento da retórica, outrora degredada, como vimos, pela revolução romântica. Mas isso, evidentemente, já é um outro capítulo da história da crítica, o qual não nos cabe aqui abordar. ${ }^{3}$

Résumé: La moderne critique littéraire prend naissance en France, au début du XIXe siècle, sous le signe du Romantisme, de l'ascension de l'Auteur et de l'Histoire dans l'horizon de la littérature, naguère incluse dans les belles-lettres. Ce texte recouvre le développement interne du paradigme historiquel biographique de la critique académique française, de Mme. de Staël (1766-1817) à Gustave Lanson (1857-1934).

\footnotetext{
${ }^{3}$ Abordamo-lo no segundo capítulo de nossa dissertação de mestrado (SOUZA, 2006).
} 


\section{REFERÊNCIAS BIBLIOGRÁFICAS}

AGUIAR E SILVA, Vítor Manuel. Teoria da literatura. 2. ed. rev. aum. Coimbra: Almedina, 1968.

AUERBACH, Erich. A filologia e suas diferentes formas. In: Introdução aos estudos literários. 2. ed. São Paulo: Cultrix, 1972. p. 11-42.

BONET, Carmelo M. Crítica literária. São Paulo: Mestre Jou, 1969.

BOURGET, Paul. O ensaio crítico em França. In: Estudos literários. São Paulo/Rio de Janeiro/Porto Alegre: W. M. Jackson Inc., 1965. (Clássicos Jackson). p. 287-302.

DE STAËL, Madame. De la littérature/De l'Allemagne: extraits. Paris: Larousse, 1935.

FRANCE, Anatole. La critique et la science. In: FAYOLLE, Roger (Org.). La critique littéraire. Paris: Armand Colin, 1964a. p. 310-311.

FRANCE, Anatole. Il n'y a pas de critique objective. FAYOLLE, Roger (Org.). La critique littéraire. Paris: Armand Colin, 1964b. p. 305-306.

IBSCH, Elrud; FOKKEMA, Douwe W. A teoria literária no século XX. In: KIBÉDI VARGA, Aron (Org.). Teoria da literatura. Lisboa: Presença, 1983. p. $30-51$

LANSON, Gustave. Des dangers de la méthode biographique en critique littéraire. In: FAYOLLE, Roger (Org.). La critique littéraire. Paris: Armand Colin, 1964. p. 320-321.

LANSON, Gustave. Histoire de la littérature française. 12. éd. Paris: Hachette, 1912.

LANSON, Gustave; TUFFRAU, Paul. Manuel illustré d'histoire de la littérature française. Paris: Hachette, 1953. 
LEMAîTRE, Jules. La critique littéraire ne peut être qu'impresșioniste. In: FAYOLLE, Roger (Org.). La critique littéraire. Paris: Armand Colin, 1964. p. 312-313.

PRADO COELHO, Eduardo. Os universos da crítica: paradigmas nos estudos literários. Lisboa: Edições 70, 1982.

ROGER, Jérôme. A crítica literária. Rio de Janeiro: Difel, 2002.

SAINTE-BEUVE, Charles-Augustin. La critique littéraire, base de la science morale. In: FAYOLLE, Roger (Org.). La critique littéraire. Paris: Armand Colin, 1964a. p. 282-283.

SAINTE-BEUVE, Charles-Augustin. L'enquête critique. In: FAYOLLE, Roger (Org.). La critique littéraire. Paris: Armand Colin, 1964b. p. 283-285.

SOUZA, Nabil Araújo de. Do conhecimento literário: ensaio de epistemologia interna dos Estudos Literários (Crítica e Poética). 2006. 568.f. 2 v. Dissertação (Mestrado em Estudos Literários) — Faculdade de Letras, Universidade Federal de Minas Gerais, Belo Horizonte.

TAINE, Hippolyte-Adolphe. A arte e o belo, segundo Taine. In: COCHOFEL, João José (Org.). Iniciação estética. 2. ed. cor. e aum. Lisboa: Europa-América, 1964a. p. 142-150.

TAINE, Hippolyte-Adolphe. La critique qui peint et la critique qui explique. In: FAYOLLE, Roger (Org.). La critique littéraire. Paris: Armand Colin, 1964b. p. 289-290.

TAINE, Hippolyte-Adolphe. La méthode de Taine appliqué à l'étude d'un auteur. In: FAYOLLE, Roger (Org.). La critique littéraire. Paris: Armand Colin, 1964c. p. 293-294.

TAINE, Hippolyte-Adolphe. Pages choisies. Paris: Larousse, 1953.

THIBAUDET, Albert. Physiologie de la critique. Paris: Nouvelle Revue Critique, 1948. 